\title{
Phase separation of composite materials through simultaneous polymerization and crystallization
}

\author{
Kosuke Sato, Yuya Oaki and Hiroaki Imai
}

Composite materials have attracted much interest because of the emergent properties originating from the components. A variety of methods have been studied to control the morphology of composites based on noncrystalline polymers and crystalline materials. However, it is not easy to control complex morphologies, such as segregated sea-island structures, on the submicrometer scale. Polymerization induces crystallization, because supersaturation, which is required for crystallization, is achieved by the consumption of the monomer. Here we report a phase-separation approach based on simultaneous polymerization and crystallization as a new method for the morphological control of composite materials. Segregated polymer and organic crystal domains are obtained by polymerization of an organic monomer solution accompanied by simultaneous crystallization. The phase separation induced the generation of composite materials consisting of a redox-active quinone crystal and conductive polymer with a segregated structure on the submicrometer scale. The segregated composite of 2,3-dichloro-1,4naphthoquinone and polypyrrole showed enhanced charge-storage properties based on the smooth redox reaction. The present phase-separation approach can be applied to a variety of functional segregated composite materials consisting of crystalline and polymer materials.

NPG Asia Materials (2017) 9, e377; doi:10.1038/am.2017.53; published online 21 April 2017

\section{INTRODUCTION}

Morphological control of composite materials has the potential to enhance their properties. ${ }^{1-3}$ The morphology of composites based on crystals and polymers can be controlled by a variety of methods. ${ }^{4-6}$ Here we show a new method for morphological control through phase separation induced by simultaneous polymerization and crystallization. This phase separation led to segregated domains of a redox-active quinone crystal and a conductive polymer on the submicrometer scale (Figure 1). The segregated composites showed improved electrochemical properties based on the smooth redox reaction of the quinone crystal.

Functional composite materials have attracted much interest because of the emergent properties originating from the components. $^{7-9}$ Polymer-mediated crystallization produces composites of inorganic crystals and organic polymers. ${ }^{4-6}$ Layered inorganic compounds form composites upon the intercalation of guest organic molecules. ${ }^{10}$ Polymer-based composites are prepared by the incorporation of inorganic fillers in the polymer matrices. ${ }^{11}$ Molecular and porous templates facilitate the formation of composites through the casting and coating of guest molecules. ${ }^{12-15}$ In general, it is not easy to prepare composites based on polymers with low solubility and processability, such as conductive polymers with rigid $\pi$-conjugated systems.

In previous reports, ${ }^{12-19}$ composites based on conductive polymers were synthesized by templating and coating coupled with polymerization. However, complex morphologies, such as phase-segregated sea-island structures on the submicrometer scale, are not easily obtained by typical methods. A new method is required for controlling the morphology of composites. Here we outline a new approach to phase separation through simultaneous polymerization and crystallization in order to control the morphology of composites. Phase separation produces segregated sea-island structures in the composite materials. This morphological control expands the range of applications of composite materials. When the phase-segregated sea-island structure is generated on the submicrometer scale in composites consisting of conductive polymers and redox-active organic crystals, the conductive network contributes to the smooth redox reaction of the organic crystals to provide improved electrochemical performance.

Phase separation from one solution phase to two phases is induced by changes in miscibility. ${ }^{20}$ Microphase separation and nanosegregation have been studied in block copolymers and self-organized organic molecules, respectively. ${ }^{21,22}$ Phase separation is used for the morphological control of polymer materials. ${ }^{23,24}$ However, current phase separation schemes cannot be applied to obtain composites of noncrystalline polymers and crystalline materials. In addition, phase separation is not achieved for polymers with low solubility because the one-phase precursor solution is not formed. In the present work, we prepared a segregated composite through phase separation based on the polymerization of pyrrole (Py) and the crystallization of a quinone derivative (Figure 1). The composite composed of the crystalline quinone derivative in the polypyrrole (PPy) matrix with a 


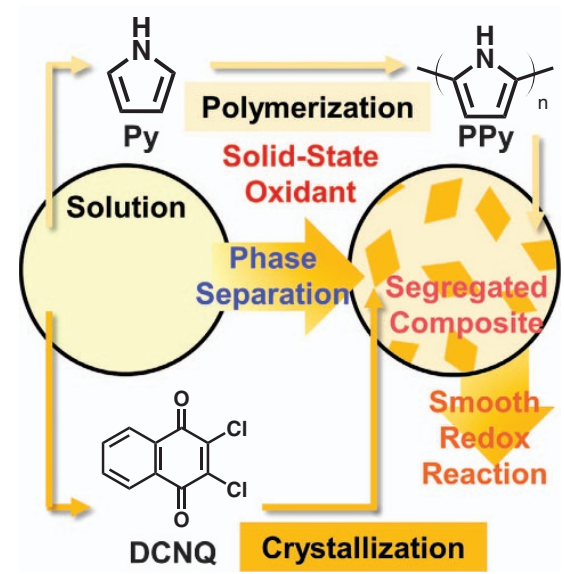

Figure 1 Schematic illustration of phase separation based on simultaneous polymerization and crystallization from a precursor Py solution containing DCNQ.

sea-island structure showed improved electrochemical properties due to its smooth redox reaction.

Redox-active organic molecules, such as quinone derivatives, have the potential for high specific capacity, originating from the multi-electron redox reaction. ${ }^{25-27}$ In general, solid crystals of quinone derivatives are not often used as active materials for charge storage because of their low conductivity and their solubility in the electrolyte solution during the redox reaction. Therefore, quinone molecules have been grafted to or loaded on carbon materials with high specific area and conductivity. ${ }^{28-30}$ Polymers containing quinone moieties have been synthesized and applied to charge storage. ${ }^{31-39}$ Our group reported another approach for the effective use of quinone derivatives, that is, the incorporation of quinone derivatives in host conductive polymers. ${ }^{40}$ However, the morphology of the composite was not controlled enough to achieve improved charge-storage properties. If the conductivity of the quinone derivatives is ensured by their incorporation in a conductive-polymer matrix, the incorporated quinone crystals can show enhanced charge-storage performance based on their smooth redox reaction. In addition, these composites have the potential to inhibit dissolution into the electrolyte solution. Crystalline quinone derivatives can be incorporated in a high-density state and inhibit dissolution during the redox reaction. Moreover, the redox reaction of the conductive polymer increases the total capacity. In the present work, the simultaneous polymerization of Py and the crystallization of a quinone derivative induced phase separation on the submicrometer scale (Figure 1).

\section{EXPERIMENTAL PROCEDURES}

\section{Synthesis of the PPy/quinone composite}

All the reagents were used as received without purification. A precursor solution containing $50 \mathrm{mg}$ of the quinone derivative was prepared with $100 \mathrm{mg}$ of neat Py liquid (Py, Tokyo Chemical Industry, Tokyo, Japan, 99\%). The precursor solution was mixed with $1.0 \mathrm{~g}$ of oxidative agent in a mortar for $5 \mathrm{~min}$. The powder was immersed in $100 \mathrm{~cm}^{3}$ of $1 \mathrm{~mol} \mathrm{dm}^{-3} \mathrm{HCl}$ and stirred for $5 \mathrm{~min}$ to remove the remaining inorganic species. The resultant black powder was collected by filtration and then dried at $60^{\circ} \mathrm{C}$. Anhydrous iron(III) chloride $\left(\mathrm{FeCl}_{3}\right.$, Junsei Chemical, Tokyo, Japan, 99.0\%), iron(III) chloride hexahydrate $\left(\mathrm{FeCl}_{3} \cdot 6 \mathrm{H}_{2} \mathrm{O}\right.$, Kanto Chemical, Tokyo, Japan, $\left.99.0 \%\right)$, iron(III) nitrate nonahydrate $\left(\mathrm{Fe}\left(\mathrm{NO}_{3}\right)_{3} \cdot 9 \mathrm{H}_{2} \mathrm{O}\right.$, Kanto Chemical, $\left.99.0 \%\right)$, copper(II) sulfate pentahydrate $\left(\mathrm{CuSO}_{4} \cdot 5 \mathrm{H}_{2} \mathrm{O}\right.$, Wako Chemical, Osaka, Japan, 99.0\%), copper(II) chloride dihydrate $\left(\mathrm{CuCl}_{2} \cdot 2 \mathrm{H}_{2} \mathrm{O}\right.$, Wako Chemical, $\left.99.0 \%\right)$ and potassium peroxodisulfate $\left(\mathrm{K}_{2} \mathrm{~S}_{2} \mathrm{O}_{8}\right.$, Wako Chemical, $\left.98.0 \%\right)$ were used as the oxidants. Naphthoquinone (NQ, Tokyo Chemical Industry, 98.0\%), tetramethyl-1,4-<smiles>O=C1C(Cl)=C(Cl)C(=O)c2ccccc21</smiles><smiles></smiles><smiles>O=C1C=CC(=O)c2ccccc21</smiles>

Scheme 1 Molecular structure of the quinone derivatives used in the present work.

benzoquinone (Tokyo Chemical Industry, 98.0\%), and 2,3-dichloro-1,4naphthoquinone (DCNQ, Tokyo Chemical Industry, 95.0\%) were used as the quinone derivatives.

\section{Characterization}

The resultant PPy and the composites were characterized by Fourier transform infrared spectroscopy (Jasco FT/IR-4200ST, Tokyo, Japan). The morphologies were observed by field-emission scanning electron microscopy (Hitachi S-4700, Tokyo, Japan and JEOL JSM-7600F, Tokyo, Japan) operated at $3.0 \mathrm{kV}$. Backscattered electron images combined with secondary electron images were obtained by another field-emission scanning electron microscopy (Carl Zeiss, Oberkochen, Germany, MERLIN VP compact) operated at $1.5 \mathrm{kV}$. The observation was performed without applying a conductive coating. The content of DCNQ in the composites was estimated by thermogravimetric analysis (Seiko TG/DTA7200, Tokyo, Japan) under air atmosphere. The crystallinity of the quinone derivatives in the composites was measured by X-ray diffraction (Rigaku, Mini Flex II, Tokyo, Japan,).

\section{Electrochemical properties}

The electrochemical properties were measured in a three-electrode glass cell with platinum $(\mathrm{Pt})$ as the counter electrode and silver/silver chloride electrode $(\mathrm{Ag} / \mathrm{AgCl})$ as the reference electrode. The electrolyte solution was an aqueous solution of $1.0 \mathrm{~mol} \mathrm{dm}{ }^{-3}$ sulfonic acid $\left(\mathrm{H}_{2} \mathrm{SO}_{4}\right)$. The working electrode was composed of $80 \mathrm{wt} \%$ active material, $10 \mathrm{wt} \%$ acetylene black as a conductive carbon and $10 \mathrm{wt} \%$ polyvinylidene difluoride as a binder. In the present work, the conductive carbon was added to ensure the conductivity, as demonstrated in previous works, ${ }^{41}$ in order to study the electrochemical properties. These materials were mixed with a small amount of $N$-methylpyrrolidone as the dispersion medium. The suspension was coated on a titanium mesh as a current collector. Cyclic voltammetry was performed at a scan rate of $1 \mathrm{mV} \mathrm{s}^{-1}$ over a potential range of -0.2 to $0.6 \mathrm{~V}$ versus $\mathrm{Ag} / \mathrm{AgCl}$ using a potentiostat (Hokuto Denko, HSV-110, Tokyo, Japan). Chronopotentiometry was performed at a current density of $0.2-5 \mathrm{~A} \mathrm{~g}^{-1}$. The cut-off potential range was -0.2 to $0.6 \mathrm{~V}$ versus $\mathrm{Ag} / \mathrm{AgCl}$ using a multi-cycle charge-discharge system (Hokuto Denko, HJ1001SD8). Hydrogen generation was not observed on the titanium mesh over this potential range.

\section{RESULTS AND DISCUSSION}

\section{Phase separation based on polymerization and crystallization}

The precursor solution of the Py monomer liquid containing a quinone derivative was placed in contact with a solid-state oxidant (Figure 1). A Py solution that was saturated with the quinone derivative, $\sim 33 \mathrm{wt} \%$, was prepared at room temperature. When the Py solution containing DCNQ (Scheme 1) was ground with copper(II) chloride dehydrate $\left(\mathrm{CuCl}_{2} \cdot 2 \mathrm{H}_{2} \mathrm{O}\right)$ powder in a mortar for $5 \mathrm{~min}$, a composite of DCNQ and PPy with a segregated structure was obtained through phase separation induced by polymerization and crystallization (Figure 2). The color of the precursor Py solution changed from red to black within $1 \mathrm{~s}$. The remaining metal species, that is, the copper-related compounds, were removed with hydrochloric acid. 
a
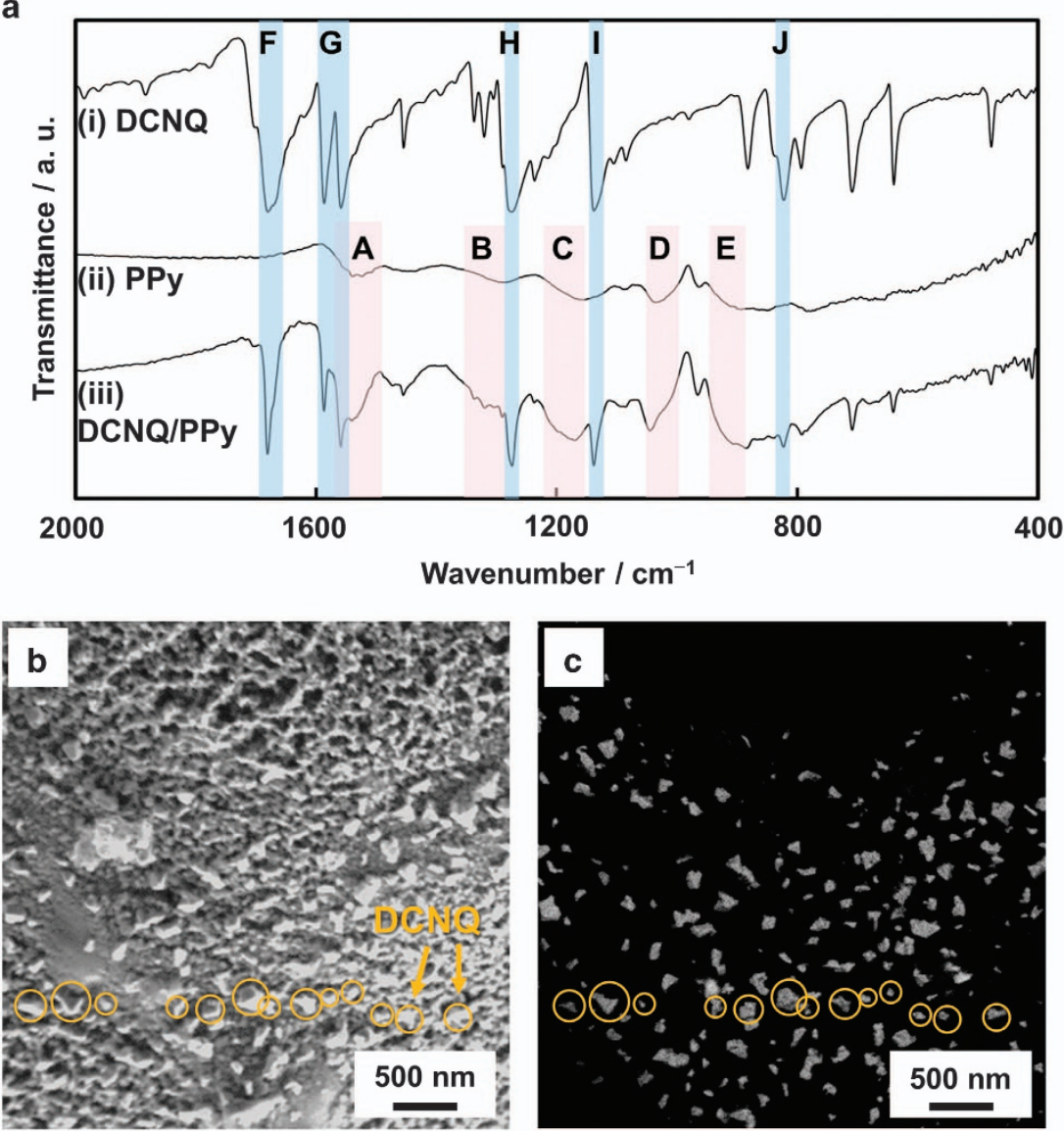

d

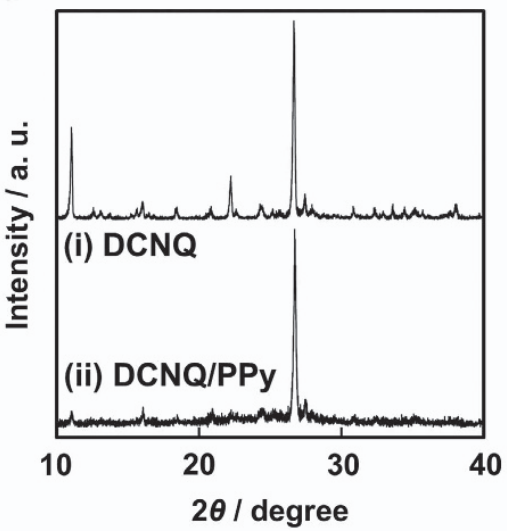

e

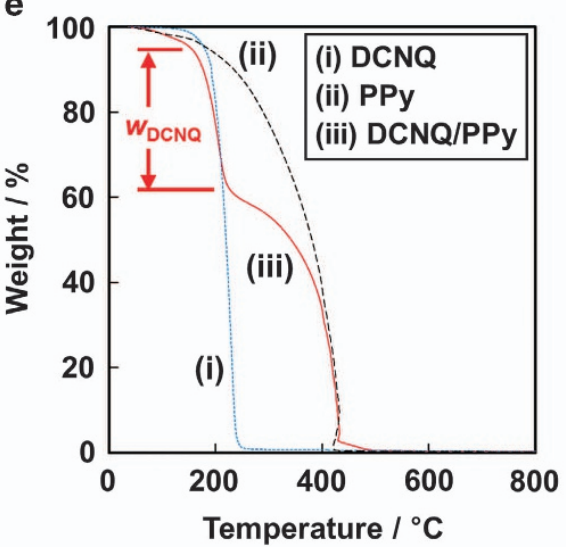

Figure 2 The DCNQ/PPy composite with segregated structure. (a) Fourier transform infrared spectra of the commercial DCNQ crystal (i), the commercial PPy microfiber (ii) and the DCNQ/PPy composite (iii). In a, the characteristic absorptions of PPy and DCNQ are denoted by the red and blue bands, respectively. Detailed peak assignments, such as A-E for PPy and F-J for DCNQ, are described in Supplementary Figure S1 in the Supplementary Information. Secondary electron (b) and the corresponding backscattered electron (c) images of the DCNQ/PPy composite by field-emission scanning electron microscopy. In b, c, the orange circles represent the positions of the DCNQ crystals. (d) X-ray diffraction patterns of the commercial DCNQ crystal (i) and the DCNQ/PPy composite (ii). (e) Thermogravimetric curve of DCNQ (i, dashed line), PPy (ii, broken line) and DCNQ/PPy composite (iii, solid line). DCNQ in (e) represents the weight content of the DCNQ in the DCNQ/PPy composite.

Absorption bands characteristic to both PPy and DCNQ were independently observed by Fourier transform infrared absorption spectroscopy (Figure 2a). The results indicate that the polymerization of Py and the crystallization of DCNQ form a composite material without the formation of any other compounds from the reaction. The resultant composite showed a sea-island structure for the DCNQ nanocrystals and PPy nanoparticles on the submicrometer scale, as observed by field-emission scanning electron microscopy (Figures $2 \mathrm{~b}$ and c). Bright island domains of DCNQ nanocrystals, with average sizes of $137 \pm 47 \mathrm{~nm}$, were observed in the backscattered electron image with electron channeling contrast (Figure 2c). The connected PPy nanoparticles, with average diameters of $50.6 \pm 8.4 \mathrm{~nm}$, formed the sea domain (Figures $2 \mathrm{~b}$ and $\mathrm{c}$ and Supplementary Figure $\mathrm{S} 1$ in the Supplementary Information). These observations suggest the 
formation of the sea-island segregated structure, as shown in Figure 1. In contrast, larger plates of DCNQ of $\sim 20 \mu \mathrm{m}$ in size were formed through recrystallization from the Py solution without oxidative polymerization (Supplementary Figure S1 in the Supplementary Information). The DCNQ/PPy composite showed peaks corresponding to the DCNQ crystals in the X-ray diffraction pattern (Figure $2 \mathrm{~d}$ ), even though the peak intensity ratio was different from that of the original DCNQ crystals. The X-ray diffraction analysis indicates that the crystals in the segregated structure are made up of DCNQ. The crystallite size was estimated to be $79.5 \mathrm{~nm}$ for DCNQ in the composite and $93.7 \mathrm{~nm}$ for the precursor bulk DCNQ, on the basis of Scherrer's equation. The crystallinity is slightly lower after polymerization, even though the actual size of the DCNQ nanocrystals was observed to be $\sim 150 \mathrm{~nm}$ in the field-emission scanning electron microscopy image. The content of DCNQ in the DCNQ/PPy composite was estimated to be $35 \mathrm{wt} \%$, approximately the same as that in the precursor solution, by thermogravimetric analysis (Figure 2e). These results indicate that the DCNQ/PPy composite had a segregated sea-island structure on the submicrometer scale made up of the DCNQ crystal and PPy nanoparticles.

In the present method, the simultaneous polymerization of Py and crystallization of DCNQ induce phase separation in the one precursor solution phase (Figure 1). When the precursor solution containing Py and DCNQ contacts the solid-state oxidant, the polymerization of Py begins in the solution phase. The resultant PPy generates the sea domain because of its immiscibility with the Py solution. At the same time, the nucleation and crystal growth of DCNQ form the island domains upon the supersaturation of DCNQ. This polymerization and crystallization continues until the Py monomer is consumed. In this way, the simultaneous polymerization and crystallization play important roles in the generation of a DCNQ/PPy composite with a segregated structure. The rapid polymerization of Py promotes the formation of the DCNQ nanocrystals of smaller size because of the rapid supersaturation.

\section{Influence of the experimental conditions on the morphology of the composite materials}

When NQ was used as the quinone derivative instead of DCNQ (Scheme 1), no composite was obtained using the same method. The reaction between NQ and Py generated a macromolecule with condensed rings (Supplementary Figure S2 in the Supplementary Information). ${ }^{42}$ In contrast, a similar segregated composite containing tetramethyl-1,4-benzoquinone crystals approximately $5 \mu \mathrm{m}$ in size was obtained using the same method (Scheme 1 and Supplementary Figure S3 in the Supplementary Information). The results imply that the higher symmetry of the molecular structure provides larger, faceted crystals. ${ }^{43}$ Moreover, the substituent on the $\alpha$ position of the carbonyl group inhibits the side reaction leading to the formation of condensed rings. The present phase-separation approach can be applied to inert and miscible combinations of monomers and crystals. The morphology of the PPy nanoparticles can be controlled by the polymerization conditions. In the present work, PPy was synthesized through oxidative polymerization at the interface between the Py solution and the solid oxidant $\mathrm{CuCl}_{2} \cdot 2 \mathrm{H}_{2} \mathrm{O}$. In our previous work, films consisting of conductive-polymer nanoparticles were obtained on the surface of inorganic oxidant crystals, ${ }^{44}$ because the oxidant crystals supply the oxidative agent with high rate and density on the surface. Similar connected PPy nanoparticles were formed in the composite as the sea domain through the same polymerization scheme (Figure 2b). When other inorganic oxidant crystals, such as iron(III) and copper(II) salts, were used as the oxidative agent, PPy particles of different sizes were obtained (Supplementary Figure S4 in the Supplementary Information). The difference in particle size is ascribed to the reaction and polymerization rate depending on the oxidative agent. The conditions of the oxidative polymerization determine the size of the DCNQ crystals during phase separation. The supersaturation of DCNQ influences the size of the crystals. In the present system, the supersaturation of DCNQ is induced by a decrease in Py monomer, which acts as the solvent, as the polymerization progresses. Therefore, the conditions of the oxidative polymerization affect the size of the DCNQ crystals. Rapid oxidative polymerization forms smaller DCNQ crystals through the rapid supersaturation. The oxidation potential, coexistent anion and hydration state of the inorganic oxidant influence the polymerization process. A previous report suggested that inorganic oxidants with higher oxidation potential facilitate rapid polymerization. ${ }^{45}$ The solid oxidants in the present work provide oxidative agents with high rate and density. However, the actual polymerization rate is controlled by the diffusion of the oxidative agent. It is inferred that the coexistent anion and water hydration inhibit the diffusion of the oxidative agents and monomers. A balance between the acceleration and inhibition effects determines the size of the PPy particles. Further detailed study is required to understand the relationship between the polymerization conditions and the particle size. In the current study, the resultant DCNQ/PPy composite is used as an active material for an electrode for charge storage. Solid $\mathrm{CuCl}_{2} \cdot 2 \mathrm{H}_{2} \mathrm{O}$ was used for the synthesis of PPy so that the DCNQ crystals were covered with smaller PPy nanoparticles (Figures $2 \mathrm{~b}$ and $\mathrm{c}$ ).

Improved electrochemical properties of the DCNQ/PPy composite DCNQ molecules in the DCNQ/PPy segregated composite were effectively used for charge storage based on their redox reaction (Figure 3). In addition, the PPy nanoparticles contributed to the specific capacity based on the redox reaction via doping and dedoping. Quinone derivatives have high theoretical specific capacity based on the two-electron redox reaction. ${ }^{25,26}$ For example, the theoretical capacity of DCNQ is calculated to be $237 \mathrm{mAh} \mathrm{g}^{-1} .^{26}$ The island-like DCNQ nanocrystals in the conductive PPy sea domain have potentials for a smooth redox reaction. The electrochemical properties were measured using a three-electrode setup in an aqueous solution of $1.0 \mathrm{~mol} \mathrm{dm}^{-3}$ sulfuric acid $\left(\mathrm{H}_{2} \mathrm{SO}_{4}\right)$. The DCNQ/PPy composite with a segregated structure showed cathodic and anodic peaks at $0.31 \mathrm{~V}$ and $0.16 \mathrm{~V}$ versus $\mathrm{Ag} / \mathrm{AgCl}$ corresponding to a reversible redox reaction between DCNQ and its reductant, as shown in the voltammogram (curve (i) in Figure 3a). The background current is assigned to the redox reaction of $\mathrm{PPy}$ upon doping and dedoping (curves (i) and (ii) in Figure 3a). A bulk DCNQ crystal $\sim 20 \mu \mathrm{m}$ in size, used as a reference, showed peaks at $0.35 \mathrm{~V}$ and $0.10 \mathrm{~V}$ (curve (iii) in Figure 3a). The difference in the potentials of the cathodic and anodic peaks, that is, the overpotential, was estimated to be $0.15 \mathrm{~V}$ for the DCNQ/PPy composite and $0.25 \mathrm{~V}$ for the bulk DCNQ crystal. The smaller overpotential of the DCNQ/PPy composite implies the smooth redox reaction of DCNQ. In addition, the specific capacity of the DCNQ/PPy composite and the bulk DCNQ was estimated to be 96.4 and $16.9 \mathrm{mAh} \mathrm{g}^{-1}$ at a scan rate of $1 \mathrm{mV} \mathrm{s}^{-1}$, respectively (Figure $3 \mathrm{a}$ ). The PPy nanoparticles, as the sea domain, facilitate smooth charge transport to the DCNQ crystals, as the island domains.

The DCNQ/PPy segregated composite presented a redox reaction at high current density (Figures $3 \mathrm{~b}$ and $\mathrm{c}$ ). The galvanostatic charge-discharge curve of the PPy/DCNQ composite had a plateau corresponding to the redox reaction of DCNQ at a current density of $1 \mathrm{Ag}^{-1}$ (curve (i) in Figure 3b). The linear change in the potential, that 
a

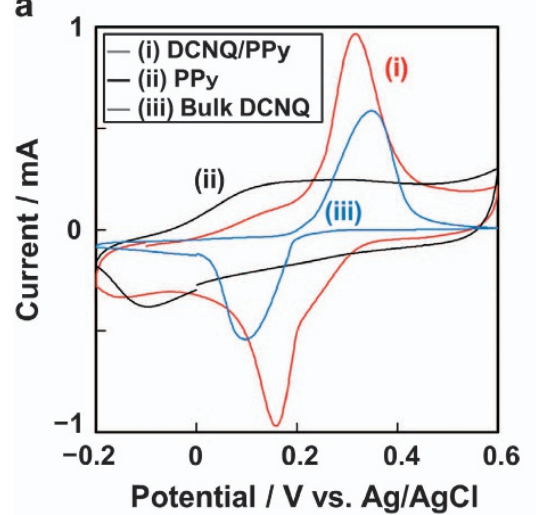

b

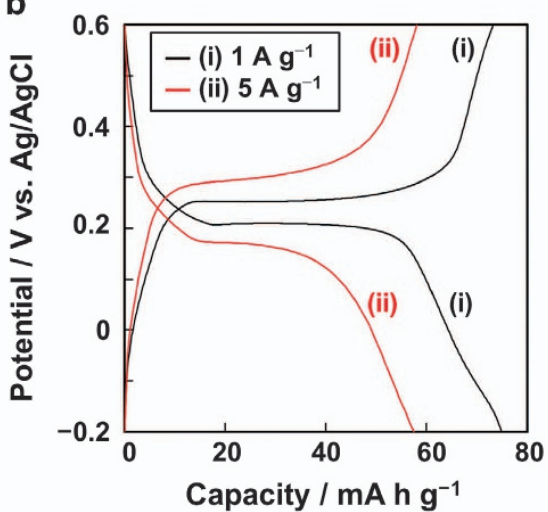

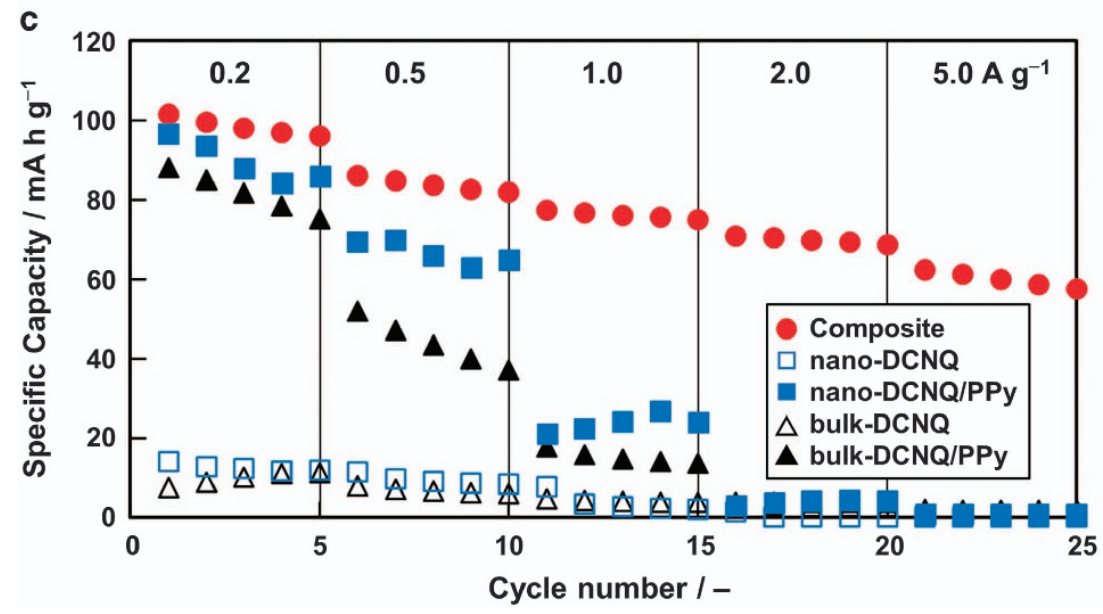

Figure 3 Electrochemical properties of the DCNQ/PPy composite and the reference samples. (a) Cyclic voltammograms of the DCNQ/PPy composite (i, red line), commercial PPy (ii, black line) and commercial DCNQ (iii, blue line) at a scan rate of $1 \mathrm{mV} \mathrm{s}^{-1}$. (b) Charge-discharge curves of the DCNQ/PPy composite at a current density of $1.0 \mathrm{Ag}^{-1}$ ( $\mathrm{i}$, black line) and $5.0 \mathrm{Ag}^{-1}$ (ii, red line). (c) Specific capacity of the DCNQ/PPy composite (filled circles), the mixture of the DCNQ nanocrystals and the commercial PPy microfiber (filled squares), the mixture of the bulk DCNQ and the commercial PPy (filled triangles), the DCNQ nanocrystals (open squares) and the bulk DCNQ crystals (open triangles) at different current densities. The reproducibility of the electrochemical properties of the DCNQ/PPy composite was verified using five samples (Supplementary Figure S5 in the Supplementary Information).

is, the slope, is ascribed to the redox reaction of PPy upon doping and dedoping. The plateau and the slope were observed at a high current density of $5 \mathrm{Ag}^{-1}$ (curve (ii) in Figure 3b). This indicates that the charge or discharge based on the redox reaction is completed within $40 \mathrm{~s}$ at $5 \mathrm{Ag}^{-1}$. DCNQ nanocrystals $500 \mathrm{~nm}$ in size (nano-DCNQ) were prepared by recrystallization. The bulk- and nano-DCNQ samples showed the same capacity of $<15 \mathrm{mAh} \mathrm{g}^{-1}$ (open squares and open triangles in Figure 3c). As the low conductivity of the DCNQ crystals inhibits smooth electrochemical reaction, including charge transport, no difference between bulk-DCNQ and nano-DCNQ was observed. Mixtures with commercial PPy microfiber $\sim 1 \mu \mathrm{m}$ in diameter were prepared on bulk-DCNQ (bulk-DCNQ/PPy) and nano-DCNQ (nano-DCNQ/PPy) in the same weight ratio as that in the segregated composite (Supplementary Figure S6 in the Supplementary Information). Nano-DCNQ/PPy showed slightly improved electrochemical properties over bulk-DCNQ/PPy (filled squares and filled triangles in Figure 3c). The improved capacity of nano-DCNQ/PPy is ascribed to an increase in the contact area between the DCNQ nanocrystals and PPy microfiber (Supplementary Figure S6 in the Supplementary Information). The segregated DCNQ/PPy nanocomposite showed enhanced capacity and cyclability (filled circles in Figure 3c). The connected PPy nanoparticles in the $\mathrm{DCNQ} / \mathrm{PPy}$ nanocomposite contribute to the improvement in the conductivity and the increase in the total capacity. These results indicate that the electrochemical properties are influenced by the composite state, including the morphology and size of both components.

In the DCNQ/PPy-segregated composite, DCNQ and PPy contributed 50.6 and $26.7 \mathrm{mAh} \mathrm{g}^{-1}$, respectively, to the total capacity of $77.3 \mathrm{mAh} \mathrm{g}^{-1}$ at $1 \mathrm{Ag}^{-1}$ (Supplementary Figure S7 in the Supplementary Information). Based on the results, $62 \%$ and $54 \%$ of the DCNQ molecules in the crystal were involved in the redox reaction at 1.0 and $5.0 \mathrm{~A} \mathrm{~g}^{-1}$, respectively (Supplementary Figure S7 in the Supplementary Information). In contrast, only 1.5\%, 2.0\%, 5.6\% and $8.9 \%$ of DCNQ molecules were involved in the bulk crystal, the DCNQ nanocrystal, the bulk-DCNQ/PPy mixture and the nano-DCNQ/PPy mixture, respectively. In previous studies, ${ }^{28-30}$ the superior utilization rate of quinone molecules adsorbed on carbon matrices was reported to be $50 \%$ at $5.6 \mathrm{~A} \mathrm{~g}^{-1}$ and $62 \%$ at $5.0 \mathrm{Ag}^{-1}$ (Supplementary Table S1 in the Supplementary Information). In these works, the dispersion of quinone derivatives on the molecular level generates the enhanced electrochemical properties. A limited number of polymers containing quinone moieties have shown higher utilization rates under the specified measurement conditions (Supplementary Table S2 in the Supplementary Information). ${ }^{32-35}$ Although crystalline quinone derivatives have the potential to be 
incorporated in the high-density state and to inhibit dissolution during the redox reaction, crystalline quinone derivatives showed lower utilization rates, such as $58 \%$ at $2.2 \mathrm{Ag}^{-1}, 6.4 \%$ at $0.5 \mathrm{Ag}^{-1}$ and $27 \%$ at $2.0 \mathrm{Ag}^{-1}$, in earlier works (Supplementary Table S3 in the Supplementary Information). ${ }^{25,31,40}$ In the present work, the utilization rate of a crystalline quinone derivative in the segregated composite was $54 \%$ at $5.0 \mathrm{~A} \mathrm{~g}^{-1}$, which is comparable to quinone molecules adsorbed on carbon (Supplementary Table S1 in the Supplementary Information). The high utilization rate is ascribed to the smooth redox reaction originating from the segregated composite structure with the PPy nanoparticles (Supplementary Figure S8 in the Supplementary Information). The DCNQ/PPy segregated composite showed both high specific capacity and the efficient utilization of DCNQ molecules in the crystals. The composition and segregated structure play important roles in enhancing the electrochemical properties. These facts suggest that our approach of incorporating crystals in a host conductive polymer is a potential strategy for the development of charge-storage devices based on small organic molecules. Further study, including morphological control, is required to improve the electrochemical properties, such as the capacity, the cycle stability and the rate performance.

\section{CONCLUSIONS}

Phase separation from simultaneous polymerization and crystallization produced a DCNQ/PPy composite with a segregated structure on the submicrometer scale. The polymerization of the precursor Py solution containing DCNQ induces phase separation through the formation of PPy and the crystallization of DCNQ. The DCNQ/PPy segregated composite showed enhanced charge-storage performance with a high utilization rate of the redox-active DCNQ crystals. The smooth redox reaction of DCNQ was achieved in the segregated composite, even at high current density. The segregated composite structure has the potential to effectively use redox-active small organic molecules for charge storage. Phase separation based on polymerization and crystallization can be applied to the syntheses of a variety of functional composite materials.

\section{CONFLICT OF INTEREST}

The authors declare no conflict of interest.

\section{ACKNOWLEDGEMENTS}

This work is partially supported by the TonenGeneral Research Foundation (YO), by the Sekisui Chemical Nature Research Program and by the Grant-in-Aid for Scientific Research (number 22107010) on Innovative Areas of 'Fusion Materials: Creative Development of Materials and Exploration of Their Function through Molecular Control' (number 2206) (HI) from MEXT. One of the authors (KS) is grateful for a JSPS research fellowship for young scientists (16J03122).

1 Mann, S. The chemistry of form. Angew. Chem. Int. Ed. 39, 3392-3406 (2000).

2 Ruiz-Hitzky, E., Darder, M., Aranda, P. \& Ariga, K. Advances in biomimetic and nanostructured biohybrid materials. Adv. Mater. 22, 323-336 (2010).

3 Kato, T., Mizoshita, N. \& Kishimoto, K. Functional liquid-crystalline assemblies: self-organized soft materials. Angew. Chem. Int. Ed. 45, 38-68 (2006).

$4 \mathrm{Yu}, \mathrm{S}$. H. \& Cölfen, H. Bio-inspired crystal morphogenesis by hydrophilic polymers. J. Mater. Chem. 14, 2124-2147 (2004).

5 Sommerdijk, N. A. \& With, G. D. Biomimetic $\mathrm{CaCO}_{3}$ mineralization using designer molecules and interfaces. Chem. Rev. 108, 4499-4550 (2008).

6 Kato, T., Sakamoto, T. \& Nishimura, T. Macromolecular templating for the formation of inorganic-organic hybrid structures. MRS Bull. 35, 127-132 (2010).

7 Okada, A. \& Usuki, A. Twenty years of polymer-clay nanocomposites. Macromol. Mater. Eng. 29, 1449-1476 (2006).
8 Yao, H. B., Fang, H. Y., Wang, X. H. \& Yu, S. H. Hierarchical assembly of micro-/nanobuilding blocks: bio-inspired rigid structural functional materials. Chem. Soc. Rev. 40, 3764-3785 (2011)

9 Haraguchi, K. Synthesis and properties of soft nanocomposite materials with novel organic/inorganic network structures. Polym. J. 43, 223-241 (2011).

10 Ogawa, M. \& Kuroda, K. Photofunctions of intercalation compounds. Chem. Rev. 95, 399-438 (1995)

11 Novak, B. M. Hybrid nanocomposite materials-between inorganic glasses and organic polymers. Adv. Mater. 5, 422-433 (1993).

12 Caruso, R. A. \& Antonietti, M. Sol-gel nanocoating: an approach to the preparation of structured materials. Chem. Mater. 13, 3272-3282 (2001).

13 Uemura, T., Horike, S. \& Kitagawa, S. Polymerization in coordination nanospaces. Chem. Asian J. 1, 36-44 (2006).

14 Ariga, K., Vinu, A., Yamauchi, Y., Ji, Q. \& Hill, J. P. Nanoarchitectonics for mesoporous materials. Bull. Chem. Soc. Jpn 85, 1-32 (2012).

15 Oaki, Y., Kijima, M. \& Imai, H. Synthesis and morphogenesis of organic polymer materials with hierarchical structures in biominerals. J. Am. Chem. Soc. 133, 8594-8599 (2011).

16 Gangopadhyay, R. \& De, A. Conducting polymer nanocomposites: a brief overview. Chem. Mater. 12, 608-622 (2000).

17 Hatchett, D. W. \& Josowicz, M. Composites of intrinsically conducting polymers as sensing nanomaterials. Chem. Rev. 108, 746-769 (2008).

18 Park, K. S., Schougaard, S. B. \& Goodenough, J. B. Conducting-polymer/ironredox-couple composite cathodes for lithium secondary batteries. Adv. Mater. 19, 848-851 (2007).

19 Nyholm, L., Nyström, G., Mihranyan, A. \& Strømme, M. Toward flexible polymer and paper-based energy storage devices. Adv. Mater. 23, 3751-3769 (2011).

20 Flory, P. J. Thermodynamics of high polymer solutions. J. Chem. Phys. 9, 660-660 (1941).

21 Hamley, I. W. Nanostructure fabrication using block copolymers. Nanotechnology 14, 39 (2003).

22 Kato, T. Self-assembly of phase-segregated liquid crystal structures. Science 295, 2414-2418 (2002).

23 Nakanishi, K. \& Soga, N. Phase separation in silica sol-gel system containing polyacrylic acid I. Gel formation behavior and effect of solvent composition. J. Non-Cryst. Solids 139, 1-13 (1992).

24 Samitsu, S., Zhang, R., Peng, X., Krishnan, M. R., Fujii, Y. \& Ichinose, I. Flash freezing route to mesoporous polymer nanofibre networks. Nat. Commun. 4, 3653 (2013).

25 Alt, H., Binder, H., Köhling, A. \& Sandstede, G. Investigation into the use of quinone compounds-for battery cathodes. Electrochim. Acta 17, 873-887 (1972).

26 Song, Z. P. \& Zhou, H. S. Towards sustainable and versatile energy storage devices: an overview of organic electrode materials. Energy Environ. Sci. 6, 2280-2301 (2013).

27 Armand, M., Grugeon, S., Vezin, H., Laruelle, S., Ribière, P., Poizot, P. \& Tarascon, J. M. Conjugated dicarboxylate anodes for Li-ion batteries. Nat. Mater. 8, 120-125 (2009).

28 Pognon, G., Brousse, T., Demarconnay, L. \& Bélanger, D. Performance and stability of electrochemical capacitor based on anthraquinone modified activated carbon. J. Power Sources 196, 4117-4122 (2011).

29 Tomai, T., Mitani, S., Komatsu, D., Kawaguchi, Y. \& Honma, I. Metal-free aqueous redox capacitor via proton rocking-chair system in an organic-based couple. Sci. Rep. 4 , 3591 (2014).

30 Chen, X., Wang, H., Yi, H., Wang, X., Yan, X. \& Guo, Z. Anthraquinone on porous carbon nanotubes with improved supercapacitor performance. J. Phys. Chem. C 118, 8262-8270 (2014).

31 Chen, C., Fu, X., Fan, W., Ma, T., Wang, Z. \& Miao, S. In-situ synthesis of core/shell structured polypyrrole/hydroquinone nano-beads and electrochemical capacitance investigations. Mater. Lett. 138, 279-283 (2015).

32 Choi, W., Harada, D., Oyaizu, K. \& Nishide, H. Aqueous electrochemistry of poly (vinylanthraquinone) for anode-active materials in high-density and rechargeable polymer/air batteries. J. Am. Chem. Soc. 133, 19839-19843 (2011).

33 Kawai, T., Oyaizu, K. \& Nishide, H. High-density and robust charge storage with poly (anthraquinone-substituted norbornene) for organic electrode-active materials in polymer-air secondary batteries. Macromolecules 48, 2429-2434 (2015).

34 Oyaizu, K., Choi, W. \& Nishide, H. Functionalization of poly (4-chloromethylstyrene) with anthraquinone pendants for organic anode-active materials. Polym. Adv. Technol. 22, 1242-1247 (2011)

35 Xu, W., Read, A., Koech, P. K., Hu, D., Wang, C., Xiao, J. \& Zhang, J. G. Factors affecting the battery performance of anthraquinone-based organic cathode materials. J. Mater. Chem. 22, 4032-4039 (2012).

36 Naoi, K., Suematsu, S. \& Manago, A. Electrochemistry of poly (1,5-diaminoanthraquinone) and its application in electrochemical capacitor materials. J. Electrochem. Soc. 147, 420-426 (2000).

37 Nokami, T., Matsuo, T., Inatomi, Y., Hojo, N., Tsukagoshi, T., Yoshizawa, H., Shimizu, A., Kuramoto, H., Komae, K., Tsuyama, H. \& Yoshida, J. Polymer-bound pyrene-4,5,9,10-tetraone for fast-charge and -discharge lithium-ion batteries with high capacity. J. Am. Chem. Soc. 134, 19694-19700 (2012).

38 Karlsson, C., Huang, H., Strømme, M., Gogoll, A. \& Sjödin, M. Polymer-pendant interactions in poly(pyrrol-3-ylhydroquinone): a solution for the use of conducting polymers at stable conditions. J. Phys. Chem. C 117, 23558-23567 (2013).

39 Karlsson, C., Huang, H., Strømme, M., Gogoll, A. \& Sjödin, M. Quinone pendant group kinetics in poly(pyrrol-3-ylhydroquinone). J. Electroanal. Chem. 735, 95-98 (2014).

40 Sato, K., Oaki, Y. \& Imai, H. Incorporation of redox-active guest in conductive and redox-active host: hierarchically structured composite of a conductive polymer and quinone derivative. Chem. Lett. 45, 324-327 (2016). 
41 Noha, K. A., Kim, D. W., Jin, C. S., Shin, K. H., Kim, J. H. \& Ko, J. M. Synthesis and pseudo-capacitance of chemically-prepared polypyrrole powder. J. Power Sources 124, 593-595 (2003).

42 Prasad, K. K. A reinvestigation of the reaction of indole with 1, 4-quinones. Tetrahedron Lett. 15, 1361-1362 (1974).

43 Weissbuch, I., Popovitz-Biro, R., Lahav, M. \& Leiserowitz, L. Understanding and control of nucleation, growth, habit, dissolution and structure of two-and three-dimensional crystals usingtailor-made'auxiliaries. Acta Cryst. B 51, 115-148 (1995).

44 Kuwabara, K., Oaki, Y., Muramatsu, R. \& Imai, H. Crystal-surface-induced simultaneous synthesis and hierarchical morphogenesis of conductive polymers. Chem. Commun. 51, 9698-9701 (2015).

45 Palaniappan, S. \& Manisankar, P. Rapid synthesis of polypyrrole nanospheres by greener mechanochemical route. Mater. Chem. Phys. 122, 1517-1521 (2010). (c) (i) This work is licensed under a Creative Commons Attribution 4.0 International License. The images or other third party material in this article are included in the article's Creative Commons license, unless indicated otherwise in the credit line; if the material is not included under the Creative Commons license, users will need to obtain permission from the license holder to reproduce the material. To view a copy of this license, visit http://creativecommons.org/licenses/by/4.0/

(C) The Author(s) 2017

Supplementary Information accompanies the paper on the NPG Asia Materials website (http://www.nature.com/am) 